\title{
FATORES CONDICIONANTES DA FORMAÇÃO DE UMA REDE HORIZONTAL ENTRE FRANQUEADAS
} CONDITIONING FACTORS TO CREATING A HORIZONTAL NETWORK WITH FRANCHISEES

\section{Luiz Henrique Figueira Marquezan}

Professor do Curso de Ciências Contábeis - Centro Universitário Franciscano - UNIFRA

\section{Marcos Antonio de Souza}

Professor do Programa de Pós-Graduação em Ciências Contábeis da UNISINOS
Data de recebimento: 10-02-2014 Data de aceite: 13-01-2015

\section{RESUMO}

O objetivo do artigo é identificar os fatores condicionantes da formação de uma rede horizontal entre franqueadas para atividades de compras. Trata-se de um estudo de caso único, desenvolvido com abordagem descritiva e qualitativa, realizado no segundo semestre de 2013. Foram pesquisados documentos de 2011 a 2013, observadas rotinas da operacionalização e entrevistados três integrantes da rede. Os principais resultados indicam que ambiente de franquias contribuiu para a aproximação dos participantes da rede, pelo conhecimento prévio e atuação conjunta, reduzindo incertezas e promovendo maior confiança. No entanto, eleva os riscos pelo aumento da confiança, tais como a não previsão do tratamento de litígios entre os participantes e os fornecedores e desistências de integrantes. Também limita a expansão da rede para categorias de compras e entrada de novos parceiros. O ambiente é restrito às empresas da franquia e os materiais primários são regulados pela franqueadora, impedindo ganhos com esses fatores.

Palavras-chave: Alianças estratégicas; redes horizontais; franquias; Teoria do Custo de Transação; economias de escala.

\section{ABSTRACT}

The objective of this article is to identify the conditioning factors to creating a horizontal network with franchisees for purchasing activities. This is a single case study, developed with a descriptive and qualitative approach, during the second half of 2013. Documents from 2011 to 2013 were researched, routines of operation were observed and three members of the network were interviewed. The main results indicate that franchising environment contributed to approximating the participants to the network, by prior knowledge and joint activities, reducing uncertainty and promoting greater trust. However, it raises the risks linked with increased trust, such as no provision of handling of disputes between participants and suppliers and member dropouts. It also limits the expansion of the network to shopping categories and entry of new partners. The environment is restricted to companies of the franchise and the primary materials are regulated by the franchisor, preventing gains with these factors.

Keywords: Strategic alliances; horizontal networks; franchises; Transaction Cost Theory, scale economies. 


\section{INTRODUÇÃO}

A formação de alianças é uma maneira das companhias obterem vantagens que isoladamente não conseguiriam ou teriam dificuldades de alcançar. Os benefícios econômicos dessas atividades podem ser obtidos de forma direta, por economias de escala e escopo (PINDYCK; RUBINFELD, 2010), ou indireta, por aprendizado organizacional, captação de informações, recursos e capacidades de parceiras (SOEKIJAD; ANDRIESSEN, 2003; POULIS; YAMIN; POULIS, 2012).

Nesse sentido, segundo Rangan e Yoshino (1996), as alianças estratégicas apresentam-se direcionadas às atividades de duas ou mais empresas que formam parceria em ações que promovam meIhor eficácia das estratégias. Esses autores apresentam três principais elementos dessas associações: (1) independência das empresas; (2) compartilhamento de benefícios e controle; (3) contribuição continuada em áreas estratégicas.

Os estudos sobre alianças e redes de empresas discutem diversos elementos relacionados, tais como (a) a combinação entre competição e cooperação, a coopetição (BENGTSSON; KOCK, 2000); (b) interesse em obter recursos e melhorar o desempenho (CHATTERJEE, 2002); (c) determinantes de parcerias entre empresas de diferentes países (CHETTY; WILSON, 2003; DONG; GLAISTER, 2006); (d) riscos na atuação conjunta (WEBER; SPARKS, 2004); (e) proteção contra novos concorrentes (POULIS; YAMIN; POULIS, 2012); (f) desenvolvimento de produtos (BADIR; BUCHEL; TUCCI, 2012); (g) determinantes das escolhas das empresas (CUMMINGS; HOLMBERG, 2012); (h) confiança (BIERLY; GALLAGHER, 2007). Tais pesquisas apresentam foco em situações nas quais competidores ou empresas que atuam em cadeias produtivas diferentes associam-se para atuar em conjunto.

Para associar-se, a premissa subjacente é a liberdade da empresa, ou seja, os elementos apresentam-se enquadrados em alianças de organizações que possuem liberdade para decisões sobre pontos estratégicos, como mercado e forma de atuação, inserção ou retirada de produtos e marcas, inovação etc. No entanto, as franquias são relações em que uma organização-mãe, o franqueador, tendo por base um contrato, se associa a empresas locais, os franqueados, para que esses vendam ou prestem serviços com os processos e a marca do primeiro (RUBIN, 1978). Essas relações apresentam reduzido grau de liberdade estratégica para os franqueados (STEPHENSON; HOUSE, 1971; KLEIN, 1995) e os direitos de decisões são fatores cruciais (BAUCUS, BAUCUS, HUMAN, 1996; MUMDZIEV; WINDSPERGER, 2013). As decisões estratégicas sobre produtos, preços, marcas e mercados normalmente ocorrem nas franqueadoras, restringindo as possibilidades de decisão das franqueadas.

As pesquisas no ambiente de franquias procuram identificar os determinantes das escolhas das empresas sobre como iniciar uma franquia (CASTROGIOVANNI; COMBS; JUSTIS, 2006) e as relações entre as partes nessa fase (BAUCUS; BAUCUS; HUMAN, 1996), discutindo também os determinantes das empresas em mesclar o uso de lojas próprias e de franqueados (DANT; KAUFMANN; PASWAN, 1992; CASTROGIOVANNI; COMBS; JUSTIS, 2006). Além desses, discutem também os aspectos que determinam os controles formais e relacionais e o desempenho da franquia (PAULINO, 2010; WRIGHT; GRACE, 2011; SOLIS-RODRIGUEZ; GONZALEZ-DIAZ, 2012; GILLIS; COMBS; KETCHEN JUNIOR, 2014). Mesmo com tais estudos, abordagens sobre franquias ainda possuem pouca ênfase na literatura (CAGLIO; DITILLO, 2008).

Em relação à parcela de pesquisas sobre a autonomia dos franqueados, encontram-se discussões acerca dos problemas de agência e de custos de transação relacionados a oportunismo, controles, governança da rede, atividades deliberadas pelos franqueados e ativos específicos investidos 
por eles, confiança e compromisso (MICHAEL, 2000; MUKHERJEE, 2003; COCHET; DORMANN; EHRMANN, 2008; WRIGHT; GRACE, 2011; JELLOJOBOR; WINDSPERGER, 2014). Ainda, em sua maioria, as pesquisas têm como pano de fundo a discussão sobre riscos vinculados à atuação dos franqueados, em virtude da reputação da marca da franquia e da qualidade dos produtos e serviços, bem como processos deliberados, discutindo os controles a serem empregados pelos franqueadores.

Diante disso, percebe-se que tanto os estudos sobre redes fora do ambiente de franquias como aqueles com análise entre franqueados e franqueadores não apresentam elementos sobre redes autônomas entre franqueados. Pela característica das restrições contratuais, a formação de redes deste tipo estaria vinculada a fatores não estratégicos. Por esse fato, as demais atividades organizacionais possuem papel operacional importante, representando alternativas relevantes no desempenho. Enquadram-se, por exemplo, os serviços de compras de materiais e serviços das atividadesmeio, não relacionados a produtos ou matérias-primas, tal como analisado nessa pesquisa.

Dada essa realidade, o objetivo do estudo é identificar os fatores condicionantes da formação de uma rede horizontal entre franqueadas para as atividades de compra. Essa pesquisa contribui com os estudos sobre redes horizontais, com destaque para a associação entre empresas franqueadas. Além disso, contribui para que as empresas possam identificar fatores que promovam ou inibam tal configuração de rede.

A importância do setor de franquias no Brasil reforça a necessidade de pesquisas nessa área, representando faturamento próximo a $\mathrm{R} \$ 116$ biIhões no ano de 2013, crescimento de 11,9\% em relação a 2012 (ABF, 2014). O ramo de alimentos, no qual se enquadra a rede de franqueadoras dessa pesquisa, representou 20,7\% desse montante, sendo o segundo no ranking dos maiores ramos de franquias no país em faturamento e líder em número de franqueadores.

Além dessa introdução, o artigo é composto por uma revisão da literatura, iniciando pela Teoria do Custo de Transação, seguido das alianças entre empresas, finalizando com o ambiente de franquias. Os procedimentos metodológicos são abordados na sequência, assim como os resultados obtidos, as considerações finais e as obras analisadas.

\section{REFERENCIAL TEÓRICO}

\subsection{Teoria do Custo de Transação}

A investigação que originou a Teoria do Custo de Transação (TCT) está relacionada aos aspectos que determinam a existência de diferentes custos nas organizações. Para isso, a transação é a unidade básica de análise e é "determinante da forma da organização" (WILLIAMSON, 1989, p. 28), relacionada à incerteza, pelos pressupostos da racionalidade limitada, assimetria de informações, oportunismo, especificidade dos ativos e frequência das relações. Para Commons (1931), as organizações surgem com o intuito da continuidade das relações, constituindo-se em estruturas com governo. O contrário são contratações por relações com o mercado, sem assistências ou garantias promovidas por essas organizações. As estruturas mistas também são abordadas por meio de contratos neoclássicos, pautados nas relações (WILLIAMSON, 1979), e podem ser associadas à formação de franquias e redes horizontais.

As relações em nível de mercado apresentam maior assimetria de informações, menor especificidade dos ativos e baixo nível de frequência das relações. No modo em que as relações ocorrem em uma organização pautada na hierarquia, o oportunismo se apresenta nas relações, em que os mecanismos de controle de execução dos contratos são elementos importantes. Em ambientes de 
configuração híbrida, como as franquias, espera-se reduzir os níveis de incerteza e oportunismo por meio dos controles técnicos e relacionais (SOLISRODRIGUEZ; GONZALEZ-DIAZ, 2012; GILLIS; COMBS; KETCHEN JUNIOR, 2014), nos quais os custos com ativos específicos são elevados por parte dos franqueados, e há alta frequência de relações entre as partes.

As diferentes formas de relações geram custos de transação de dois tipos: antes das transações (ex ante) e após os contratos (ex post). Nas ex ante há a redação, negociação e salvaguarda dos contratos; ex post referem-se à manutenção do contrato e tratamento de problemas de não cumprimento (WILLIAMSON, 1989). O investimento em custos ex ante está relacionado à redução de conflitos e litígios entre franqueador de franqueado que geram custos ex post ao contrato (MICHAEL, 2000), visões dos controles exercidos pelo franqueador. Nesse sentido, a completude dos contratos está relacionada à maturidade da franquia, indicando que a experiência do franqueador leva à elaboração de mecanismos ex ante mais efetivos (SOLIS-RODRIGUEZ; GONZALEZ-DIAZ, 2012). No entanto, estes autores identificaram que o ambiente de interação constante da franquia pode levar à substituição entre mecanismos formais e relacionais de governança, visto que os riscos de expropriação são bilaterais.

\subsection{Alianças entre empresas}

Uma aliança entre organizações pode ser entendida como "qualquer relacionamento voluntariamente iniciado e duradouro entre duas ou mais organizações que envolve a partilha, troca ou codesenvolvimento de recursos (por exemplo, capital, tecnologia, ou rotinas organizacionais)" (GILLESPIE; GULATI, 2001, p. 393). Quanto às formas, podem ocorrer por contratos sem compartiIhamento de capital, ou acordos acionários, que incluem empreendimentos conjuntos (YOSHINO; RANGAN, 1996).

Yoshino e Rangan (1996) identificam alianças estratégicas por: (a) as empresas continuam independentes; (b) compartilham o benefício e controlam o desempenho das tarefas; (c) contribuem continuamente em áreas estratégicas. Destacam também a transferência contínua de tecnologia, produtos ou qualificações e o controle compartiIhado. Devlin e Bleackley (1988) destacam mudança radical ou melhora da posição competitiva das empresas como características.

Entre as motivações para associar-se estão: redução da competição entre concorrentes aliados; acesso a recursos; capacidades e conhecimentos; economias de escala. Também se pode obter ganhos por meio da especialização em etapas da cadeia e melhora no fluxo de informações e recursos (EBERS, 2001). A premissa é o interesse em atingir objetivos que sozinha não conseguiria ou teria dificuldades.

Nesse ponto pode ser vinculada a Visão Baseada em Recursos (RBV) (BARNEY, 1991, 1995), pela obtenção de vantagem competitiva sustentável, por recursos e capacidades, tratados como "recursos estrategicamente relevantes". Em contrapartida, Rangan e Yoshino (1996) abordam a importância de não compartilhar com concorrentes as competências essenciais e vantagens estratégicas.

Nas redes, os ganhos promovidos por escalas maiores originam-se de especialização nas atividades, flexibilidade de produção e insumos, e compra de insumos em maiores quantidades (PINDYCK; RUBINFELD, 2010) ou o compartilhamento de serviços, (CHETTY; WILSON, 2003). As alianças ocorrem fora dos elos hierárquicos de uma cadeia de valor (horizontal, entre concorrentes) ou entre empresas de diferentes estágios da mesma cadeia de valor (vertical). Independentemente do modelo, a confiança aparece como determinante de sua manutenção, impactando em desempenho (SILVA, 
BRADLEY; SOUSA, 2012) e troca de informações (SOEKIJAD; ANDRIESSEN, 2003).

Powell (1990) apresenta como características das redes: complementaridade de forças; base nas relações; resolução de conflitos por normas de reciprocidade, preocupações de reputação; médio grau de flexibilidade; médio a alto grau de compromisso; benefícios mútuos; interdependência. Para estudo e desenvolvimento de alianças, encontram-se modelos distintos, mas com semelhanças. Gulati (1998) identifica cinco questões-chave: (1) formação de alianças; (2) estrutura de governança; (3) evolução das alianças; (4) desempenho; (5) consequências de desempenho para as empresas (benefícios). Devlin e Bleackley (1988) apresentam três pontos: (1) decisão de formar uma aliança; (2) escolha dos parceiros; (3) planejamento e gestão da aliança. Hoffmann e Schlosser (2001) incluem a identificação dos motivos de cooperar e a previsão de encerramento.

\subsection{Ambiente de franquias}

Relações entre empresas no ambiente de franquias possuem a coordenação e o controle dos estágios de produção e distribuição por meio de regras e obrigações (STEPHENSON; HOUSE, 1971). A possibilidade de expansão da ação é multiplicada, pois outras empresas associam-se (franqueadas) à outra (franqueadora), realizando investimentos individuais (STEPHENSON; HOUSE, 1971; RUBIN, 1978; KLEIN, 1995). Os determinantes das escolhas das franqueadoras e a configuração das franquias podem ser analisados por diversos aspectos teóricos, incluindo questões das teorias de agência, sinalização, visão baseada em recursos, escassez de recursos, institucional e custos de transação (COMBS; KETCHEN JUNIOR, 2003; DANT; KAUFMANN, 2003; COMBS; KETCHEN JUNIOR; HOOVER, 2004; COMBS; MICHAEL; CASTROGIOVANNI, 2004; CASTROGIOVANNI; COMBS; JUSTIS, 2006).
Um dos elementos discutidos é o grau de decisão de cada uma das partes. Stephenson e House (1971) abordam um exemplo em que a franqueadora decide: forma das operações diárias; localização da franqueada; instalações físicas; seleção de fornecedores; sistemas contábeis; materiais; precificação; mix de produtos. É vertical, com restrições legais e mecanismos de autocumprimento das obrigações, definindo limites de ação da franqueadora e franqueadas (KLEIN, 1995). Assim, um fator crítico da gestão das franquias é o grau de autonomia das franqueadas (STEPHENSON; HOUSE, 1971; COCHET; DORMANN; EHRMANN, 2008) e apresenta-se ligado a problemas de agência, por comportamentos oportunistas. No entanto, Mukherjee (2003) identificou comportamentos deliberados dos franqueados (free-riding), com aspectos positivos à qualidade, no qual um franqueado tende a copiar procedimentos favoráveis de outros.

Outros pontos decisivos para a manutenção da rede são o apoio da franqueadora, a atuação dela em concorrer ou adquirir lojas de franqueados (DANT; KAUFMANN; PASWAN, 1992) e o estágio do ciclo de vida da relação, em que as franqueadas sentem-se mais independentes conforme a relação evolui e podem apresentar comportamentos deliberados, uma não conformidade ao contrato de franquia (BAUCUS; BAUCUS; HUMAN, 1996; FRAZER, 2001; MUKHERJEE, 2003; WRIGHT; GRACE, 2011). Assim como em outras relações interorganizacionais, o papel da confiança é determinante, influenciado positivamente pela satisfação da franqueada e negativamente por conflitos (HOLMBERG; MORGAN, 2003).

Outros estudos sobre franquias abordam outra forma, com relações semelhantes a redes, vinculada, principalmente, à troca de informações sobre atividades, tecnologias e desenvolvimento dos negócios (PASWAN; WITTMAN, 2009). Outras pesquisas (NAULT; DEXTER, 1993; NAULT, 1997; MUKHERJEE, 2003;COCHET; DORMANN; 
EHRMANN, 2008) discutem realidades em que franqueados possuem territórios e clientes específicos, com externalidades positivas entre eles, relacionadas principalmente aos efeitos de investimentos dos franqueados. Entretanto, mesmo prevendo interação entre eles, não abordam autonomia para atividades independentes em conjunto.

\section{METODOLOGIA DE PESQUISA}

A pesquisa caracteriza-se como estudo de caso único (YIN, 2005), ao analisar em profundidade a formação de uma rede horizontal entre empresas franqueadas para compras compartilhadas. Possui abordagem qualitativa e descritiva (GODOY, 1995) em evidências analisadas com foco na interpretação da observação, documentos e entrevistas, procurando ligações entre os eventos do fenômeno (TRIVIÑOS, 1987).

Por questões de sigilo das empresas, caracteriza-se a franquia em que a rede foi formada como sendo composta por cerca de 20 grandes empresas franqueadas com maioria de capital nacional familiar. A franquia atua no Brasil há mais de 50 anos, no setor de alimentos. $\mathrm{O}$ caso objeto de estudo apresenta uma rede independente em relação à franqueadora, na qual ela não atua na determinação, coordenação e controle das atividades, que ocorreu em dois momentos, conforme a Figura 1: (1) parceria temporária com 4 franqueadas, tratada como "projeto", de 2011 a 2012; (2) avaliações e aprendizados do projeto resultaram na aliança de longo prazo, abordada como "aliança", com participação de outras franqueadas, incluindo a franqueadora como usuária.

Para análise foi utilizado o framework de Hoffmann e Schlosser (2001), obtido na pré-análise dos materiais (BARDIN, 2010). Mesmo concebido em alianças entre médias empresas, entende-se que o modelo é adequado ao estudo, por abordar desde a decisão de cooperar até a previsão de finalização da aliança. A ele foram associadas características das franquias, conforme o Quadro 1.

A TCT foi incorporada, procurando identificar: (a) custos de transação ex ante e ex post; (b) negociação; (c) definições de obrigações e direitos; (d) previsões de saídas; (e) estruturas criadas; (f) estruturas existentes; (g) ações contra comportamentos oportunistas; (h) ações punitivas ou tratamentos de atitudes imprevistas; (i) benefícios.

Tendo por base as categorias de análise, os dados foram coletados em entrevistas semiestruturadas, análise de documentos (Quadro 2) e observação direta. A observação ocorreu no ambiente da franqueada B, sobre a operacionalização das compras em rede, com acompanhamento contínuo dos funcionários. Para a observação e a análise dos documentos foi utilizado como guia o mesmo roteiro das entrevistas, na busca por respostas para as questões antes das intervenções dos respondentes, resultando em melhor obtenção de informações, principalmente nos pontos não abordados espontaneamente pelos entrevistados.

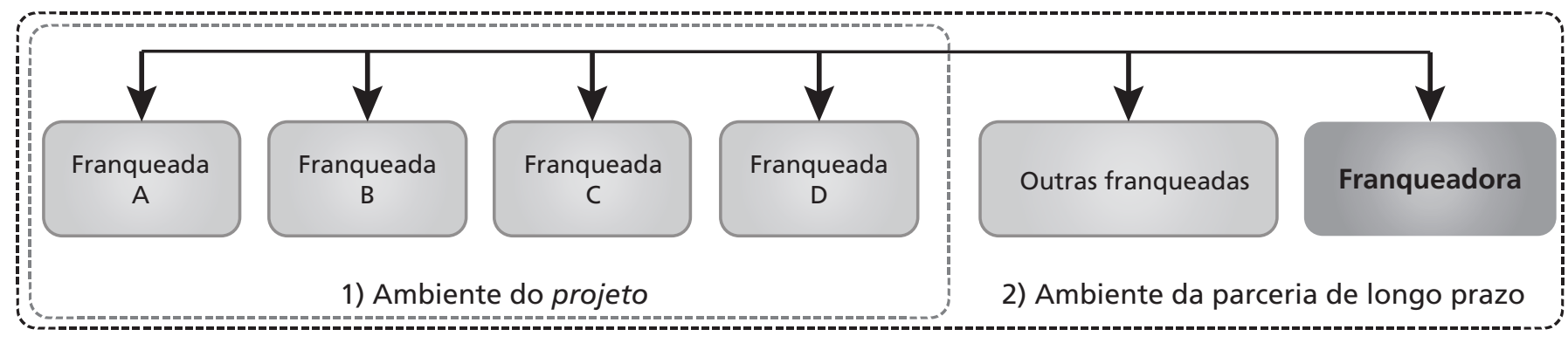

Figura 1: Rede horizontal

Fonte: Dados da pesquisa. 
Quadro 1: Categorias de análise

\begin{tabular}{|l|l|}
\hline \multicolumn{1}{|c|}{ Hoffmann e Schlosser (2001) } & $\begin{array}{l}\text { Particularidades do ambiente de franquias - Stephenson e House (1971); Klein, } \\
\text { (1995); Frazer (2001) }\end{array}$ \\
\hline Análise estratégica e decisão em cooperar & $\begin{array}{l}\text { Limitações de ação, por definições da franqueadora quanto aos produtos e processos } \\
\text { de marketing e execução de vendas. }\end{array}$ \\
\hline Escolher um parceiro & $\begin{array}{l}\text { Facilidades ou dificuldades por serem franqueadas; relações já existentes; restrições à } \\
\text { participação de empresas fora da franquia. }\end{array}$ \\
\hline Desenhar a parceria & $\begin{array}{l}\text { Existência prévia de contratos de direitos e deveres com a franqueadora; semelhança } \\
\text { nas operações, contribuições para a aliança ou falta delas; compartilhamento de } \\
\text { competências pela ausência de competição direta. }\end{array}$ \\
\hline Implementar e gerenciar a parceria & $\begin{array}{l}\text { Franqueadora como elo entre franqueadas (informações, gestão, análise de } \\
\text { desempenho etc.); coordenação e controle; apoio ou inibição da franqueadora. }\end{array}$ \\
\hline Encerramento da parceria & Troca de franqueadas; encerramento do contrato de franquia. \\
\hline
\end{tabular}

Fonte: Autores citados.

Quadro 2: Documentos analisados

\begin{tabular}{|c|l|}
\hline Documento & \multicolumn{1}{|c|}{ Conteúdo } \\
\hline Doc1 & Proposta da empresa terceirizada para a implementação do projeto. \\
\hline Doc2 & Contrato entre as empresas, para a fase do projeto. \\
\hline Doc3 & Cálculo do potencial de ganho de uma das franqueadoras, na fase do projeto. \\
\hline Doc4 & $\begin{array}{l}\text { Relatório de avaliação de uma categoria de compra, com os ganhos esperados e efetivamente realizados, na } \\
\text { fase do projeto. }\end{array}$ \\
\hline Doc5 & $\begin{array}{l}\text { Apresentação dos resultados parciais, na fase do projeto, de uma das franqueadoras, nas diversas categorias de } \\
\text { compra. }\end{array}$ \\
\hline Doc6 & Apresentação dos resultados parciais, na fase do projeto, de toda a rede, nas diversas categorias de compra. \\
\hline Doc7 & Planilha detalhando os resultados, na fase do projeto, de uma das categorias de compra. \\
\hline Doc8 & Planilha detalhando todos os resultados do projeto. \\
\hline
\end{tabular}

Fonte: Dados da pesquisa.

Realizaram-se entrevistas com três integrantes da rede, em novembro e dezembro de 2013: (a) o líder do projeto, funcionário da franqueada A (EntrA); b) funcionários das franqueadas B e C (EntrB e EntrC) ligados à rede. O roteiro das entrevistas foi testado com um funcionário do setor de compras da franqueada B, participante da operacionalização da rede.

As evidências foram agrupadas em fonte secundária, representada por uma matriz, tendo nas linhas as categorias de análise e nas colunas as fontes dos dados: entrevistados, documentos e anotações das observações. Assim, tem-se a segunda fase da análise de conteúdo (BARDIN, 2010), a exploração do material coletado, que inclui a organização das evidências ao agrupá-las nas categorias (indicadores para Bardin).
Por fim, as evidências foram interpretadas pela matriz, permitindo dois tipos de leitura: (1) análise da categoria e suas características principais, na comparação entre as várias fontes de dados; (2) por fonte de dados, em que a unidade de análise pode ser vista pela interpretação do documento utilizado ou pela ótica de um determinado entrevistado. Interpretações e análises são apresentadas no próximo tópico.

\section{APRESENTAÇÃO E ANÁLISE DOS DADOS}

\subsection{A rede horizontal entre franqueadas}

A rede formada, dada a natureza da relação anterior entre as empresas enquanto franqueadas, apresenta particularidades que podem 
ser analisadas no escopo do trabalho seminal de Powell (1990). Fatores como a complementariedade, ambiente relacional, médio grau de flexibilidade, alto grau de compromisso e visão de benefícios mútuos estão presentes na rede analisada.

Outras duas características da rede podem ser destacadas: (a) menor evidência de fatores determinantes da rede, tais como a interdependência pelas empresas tendo em vista manterem suas estruturas iniciais; (b) menor preocupação com fatores relacionados à reputação da rede e à resolução de conflitos, devido ao maior grau de confiança decorrente da franquia. São aspectos mais amplamente discutidos nas análises que seguem.

\subsubsection{Análise estratégica e decisão em cooperar}

A formação da rede em análise, entre as franqueadas, surgiu por iniciativa do diretor-presidente de uma das companhias. Todos os entrevistos indicaram tal ponto, destacando a percepção de ganhos financeiros na redução de custos dos materiais comprados pelo aumento da escala como principal motivador. O fato das empresas já atuarem em sistema compartilhado de comitê de compras, que negocia com fornecedores os materiais básicos, é percebido como contributivo nesse processo.

A economia, segundo os entrevistados, está vinculada à consolidação dos volumes de aquisição de materiais secundários, de uso comum às empresas. No contrato é previsto que "A CONTRATANTE pretende reduzir seus custos de aquisição de produtos e serviços em diversas categorias". Nesse ponto, a semelhança entre as empresas é fator contributivo para uma maior sinergia nas categorias de compra conjunta.

\subsubsection{Escolha dos parceiros}

O ambiente de franquia em que as empresas atuam já as conectava mesmo antes da formação dessa rede. Seus dirigentes eram conhecidos e a reputação delas já está consolidada pela própria continuidade no sistema da franquia, pois, nenhuma das empresas do projeto possui menos de 10 anos de atuação. Assim, a proximidade dada pelas atividades anteriores e o nível de confiança dado pelo histórico de reputação são motivadores da rede.

Na fase do projeto, a rede aconteceu apenas entre quatro empresas. A proximidade entre os presidentes das companhias foi apontada pelos três entrevistados. Além disso, o EntrA, líder do projeto, indicou que a proximidade física e de porte também foi determinante. As franqueadas $A, C$ e $D$ atuam em estados próximos e possuem portes semelhantes. A franqueada B foi convidada pelas demais por ser uma das menores companhias, o que indicava a oportunidade de ganho ao consolidar os volumes de compras.

Na fase da aliança, em que os aprendizados obtidos foram compartilhados com as outras franqueadas do sistema, decidiu-se por ampliar a rede a todos os interessados. Apenas uma das empresas, a maior delas, optou por não aderir à rede. Segundo os entrevistados A e C os motivos dessa não participação relacionam a: (1) já ter um grande volume próprio, ou seja, os ganhos pela rede seriam menores; (2) a empresa ser multinacional, tendo sua própria central de compras em outro país.

Assim, além do contato anterior entre as empresas, para o projeto, os portes semelhantes, que levam à expectativa de ganhos em categorias semelhantes, e a proximidade regional foram decisivos na escolha. Para a aliança, o único determinante é a existência prévia da relação de franquia, uma vez que todos tiveram oportunidade de participar.

O ambiente de franquia também levou a duas outras particularidades: (a) não há previsão para entrada de parceiros fora do sistema, o que limita a expansão do volume, mesmo que a expansão seja com empresas de outros segmentos, não concorrentes; b) interesse da franqueadora em participar como beneficiária da rede. Essa segunda 
particularidade se encontra na forma de interesse, ainda não executado pela franqueadora, uma vez que sua composição e operação são muito diferentes de seus franqueados. Carece, portanto, de que ajustes operacionais ainda sejam feitos pela franqueadora. No entanto, para questões vinculadas à conformidade dos franqueados, os controles relacionais provenientes dessa atuação podem atuar como mecanismos de governança, tal como enfatizado por Cochet, Dormann e Ehrmann (2008).

Além dos aspectos já destacados, o relacionamento já existente parece elevar o grau de confiança entre os parceiros. Quando indagados sobre problemas entre as empresas e fornecedores, tais como desistências e inadimplência, os entrevistados indicaram que entendem isso como algo remoto e não previsto. Nesse sentido, a reputação das empresas é ressaltada claramente quando o EntrA declara que "não é qualquer empresa que pode ser um franqueado, [...] todas já tem uma história". No entanto, reconhece a lacuna que pode prejudicar a reputação da rede. Para a aliança, como está em construção, o entrevistado defende que um modelo de governança estruturado deve prever tal situação.

\subsubsection{Desenho da parceria}

Quanto à forma de desenvolvimento da rede, exclusivamente para o projeto, as franqueadas efetuaram a contratação de uma empresa já experiente em unir organizações para compras compartilhadas. A essa empresa coube o papel de operacionalizar as atividades da rede. A aquisição, por parte das franqueadas, dos conhecimentos prévios da terceirizada são oportunidades de ganho não financeiro. Na aliança foi criada uma central de compras, tendo como sede a estrutura já existente da associação das franqueadas, sem a participação da empresa terceirizada. Os diferentes modelos geram custos de transação diferentes: no primeiro há custos de remuneração variável relativos aos ganhos conseguidos pela empresa terceirizada; no segundo há o custo fixo de manter a estrutura da central de compras, com pessoal contratado para essa função, sendo que os gastos da associação são custeados pelas franqueadas, na proporção de sua participação no volume de vendas da franquia.

Quanto ao escopo das categorias de compras, por meio dos documentos analisados percebe-se que a rede foi desenvolvida com escopo mais restrito na fase de projeto. Os entrevistados indicaram que o volume financeiro de ganho e a complexidade da categoria (uniformidade entre parceiros e dificuldades de negociação ou definição de fornecedores comuns) foram determinantes da escolha das categorias que efetivamente foram negociadas, conforme apresentado no Quadro 3 (na página seguinte).

Nesse sentido, o EntrC indicou que o projeto não é simples, mesmo com categorias de produto que aparentemente não possuem alto grau de complexidade. Exemplifica no caso de combustíveis, que foi um dos maiores gargalos de compra, pela impossibilidade de negociação com poucos fornecedores, pela abrangência territorial entre as franqueadas e de suas áreas de atuação.

Para a aliança, o EntrB informou que está sendo analisado um escopo maior, de até 50 categorias, com previsão de transferência da negociação individual das franqueadas para a central de compras até 2015. Nesses casos, os custos de negociação ocorrem em dois momentos: (1) negociação entre os membros da rede na prioridade das categorias; (2) harmonização dos itens, para consolidação dos volumes.

Quanto ao papel de cada participante nos diversos processos relativos às compras, foi definido, em ambas as fases, que as negociações com os fornecedores seriam realizadas fora do ambiente das franqueadas. Na fase do projeto, foi realizada pela empresa terceirizada, em sua sede e, na aliança, por uma central de compras, com pessoal dedicado, na sede da associação das franqueadas. No entanto, pela própria natureza de aprendizado do projeto, 
Quadro 3: Categorias de compras: previsão versus execução

\begin{tabular}{|l|l|}
\hline \multicolumn{1}{|c|}{ Doc1 - projeto planejado } & \multicolumn{1}{c|}{ Doc8 - projeto realizado } \\
\hline Não prevista & Cesta Básica (benefício) \\
\hline Combustíveis e lubrificantes & Combustíveis \\
\hline Não prevista & Copos descartáveis \\
\hline Embalagens & Embalagens \\
\hline Energia elétrica & Não adotada: diversidade nas formas de negociação \\
\hline Equipamentos de Proteção Individual (EPI) & Equipamentos de Proteção Individual (EPI) \\
\hline Não prevista & Locação de frota \\
\hline Manutenção predial & Não adotada: parcerias e contratos firmados anteriormente. \\
\hline Material de escritório & Material de escritório \\
\hline Refeição & Não adotada: restrições das áreas que gerenciam nas empresas \\
\hline Serviços terceirizados & Não adotada: diversidade de serviços e fornecedores \\
\hline Tecnologia da informação/telecomunicações & Não adotada: restrições das áreas que gerenciam nas empresas \\
\hline Não prevista & Uniformes \\
\hline Viagens e estadias & Não adotada: diversidade de serviços e fornecedores \\
\hline
\end{tabular}

Fonte: Dados da pesquisa.

houve a necessidade de participação de membros das franqueadas nas negociações da rede com os fornecedores, conforme relata o EntrC.

Além disso, no projeto, após a escolha dos fornecedores, a terceirizada ofereceu suporte para definições das condições comerciais no estabelecimento dos contratos, promovendo o aprendizado das franqueadas e auxiliando na garantia dos contratos firmados. Em ambas as fases, os processos de pedidos de compras, definição dos prazos de entrega e pagamento são realizados diretamente pela franqueada. Essa fase final diminui os custos de transação, por ser uma relação menos complexa, entre um comprador e um fornecedor, porém aumenta a incerteza quanto aos procedimentos adotados por cada comprador, que podem afetar a reputação da rede, como uma eventual inadimplência.

\subsubsection{Implementar e gerenciar a parceria}

Para a fase do projeto foi contratada uma empresa para atuar nas negociações da rede. Ela possui experiência nessa atividade e elencou premissas para o sucesso da formação da rede: decisão dos fornecedores por empresa, ou seja, sem imposições, e formação de contratos individuais; negociação de todo o volume conjunto; a terceirizada passa conhecimentos e metodologias para as participantes da rede, de forma a continuar com os ganhos após o fim do projeto; alta dedicação das franqueadas no fornecimento de informações e participação, conforme a necessidade, na validação de materiais e auxílio na negociação com fornecedores.

Pode-se destacar a importância das franqueadas não efetuarem negociações paralelas, ou seja, fora da rede, apontadas pelo líder do projeto como um risco potencializado pelo assédio dos fornecedores. Segundo o EntrA, os fornecedores percebem a negociação em conjunto como redução de suas margens e tentam atuar diretamente nas franqueadas, o que necessita comprometimento delas para a não ocorrência. Destaca ainda que isso enfraqueceria a parceria por ganhos de curto prazo, com perdas das reduções de custos no longo prazo.

Também foram constatadas algumas obrigações contratuais (Doc2) previstas para as franqueadas no projeto: instituir equipe e políticas sobre a rede; indicar um gerente do projeto; fornecer informações; validar cronograma, volumes e outras partes, resultados de negociações etc.; pagar a terceirizada; pagar despesas fora da 
proposta inicial. Alguns desses fatores elevam os custos de operacionalização da rede, que precisam ser compensados pelos ganhos obtidos nas negociações.

Sob essas e outras premissas e obrigações contratuais no projeto, foi apresentado um modelo de seis fases para a implementação das compras, em cada categoria, realizado pela empresa terceirizada, com apoio das franqueadas: "1 - Validação do levantamento preliminar de dados; 2 - Análise do mercado fornecedor; 3 - Elaboração do modelo de contratação; 4 Realização do processo de cotação; 5 - Realização do processo de negociação; 6 - Suporte ao fechamento dos contratos". As franqueadas atuavam principalmente nas fases 1 e 6 , tendo papel de validação conjunta nas demais.

Ainda no projeto, a empresa terceirizada passava a ter direito à remuneração dos ganhos a partir da aceitação da etapa 5, na qual ela entregava às franqueadas todo o resultado da negociação. Isso reduzia a incerteza sobre manobras das franqueadas que pudessem prejudicar sua remuneração por desistências ou alterações de intenção. Apesar disso, EntrB relatou o problema ocorrido em uma categoria, em função do fornecedor não atender à demanda contratada, o que incorreu na devolução de parte do valor recebido pela terceirizada.

Um fator preponderante para a implementação da rede foi sua aceitação pelos funcionários das áreas de compras das franqueadas. Em casos assim há incerteza sobre a manutenção das estruturas vigentes, como uma economia de custos para as franqueadas. O EntrA indicou que tal aceitação é ponto chave do processo, dado que o convencimento dos diretores foi mais simples, pois, tratava-se de redução de custos, enquanto nas equipes de compras certas deficiências operacionais poderiam aparecer. Isso causou certa resistência inicial, tratada diretamente nas franqueadas.
Além disso, os relatos das entrevistas indicam que a suspeita de redução de estrutura interna não se concretizou, uma vez que os setores de compras das franqueadas foram mantidos, principalmente em função da maior intensidade de trabalho na implantação da rede, relacionada ao envio de informações e validação de cada etapa, de cada categoria de compra. No projeto foram criados três grupos de trabalho, o que demandou atividades extras das equipes das franqueadas. São eles:

1) comitê diretivo: formado pela direção das empresas e um representante da terceirizada, atuava em macro decisões, conflitos, qualidade do projeto, apoio organizacional e acompanhamento da evolução;

2) gerência do projeto: um responsável por franqueada e um gerente da terceirizada, para coordenar equipes e decisões, supervisão e validação das etapas e atividades, interações entre áreas, preparar materiais para comitê e facilitar o andamento do projeto;

3) equipe de projeto: setores de compras, custos e finanças das empresas, um consultor e um analista da terceirizada, responsáveis pelo levantamento de dados, desenvolvimento de materiais, cenários, relatórios e validação de produtos.

Sobre a fase da aliança, os entrevistados indicaram que tais estruturas se mantiveram visto que as atividades de negociação foram substituídas por outras relacionadas à colocação de pedidos, controle de manutenção dos contratos negociados pela central, controle de estoques mínimos e documentações para certificações de fornecedores, entre outras. Assim, elevaram-se os custos totais de transação, representados pela central de compras e pelas estruturas nas franqueadas. Isso pode ser resultado da rede ainda estar em formação, não negociando todas as categorias de compra, como indicado por um dos entrevistados, afirmando que a nova central de compras irá atuar de forma mais completa. Isso indica que a redução das estruturas das empresas ainda pode ocorrer, o que geraria economia de custos. 


\subsubsection{Encerramento da parceria}

No projeto havia a previsão de encerramento, justamente pela proposta de testar e aprender na formação dessa rede, com número restrito de parceiros. Além disso, houve previsão de eventos para inibir o encerramento involuntário ou indesejado da rede, com previsão de multa por desistência de categoria de compra ou encerramento da rede sem justificativa, obrigando a finalização das atividades já em curso entre franqueadas e terceirizada. A contratação da empresa trouxe à rede conhecimento para atuar com maior prevenção, devido à terceirizada atuar com outras empresas, em ambientes de maior incerteza.

No modelo de aliança, não há previsão. Novamente, o ambiente de franquia com relações anteriores e duradouras entre as empresas apresenta-se como determinante. Os entrevistados indicaram como "muito difícil" o encerramento da rede, pois, mesmo com a saída de uma empresa do sistema de franquia, outra assumirá suas atividades.

Isso reforça o entendimento do EntrA sobre a necessidade de ser definida uma governança da rede (COCHET; DORMANN; EHRMANN, 2008) capaz de suprir tais lacunas, e tende a ser considerado em futuros contratos, advindos da experiência de atuar em conjunto (SOLIS-RODRIGUEZ; GONZALEZDIAZ, 2012). Nesse ponto das conversas, a reação dos entrevistados foi de surpresa quanto a possíveis saídas de membros, afirmando ser algo importante que precisa de análise. Isso indica uma maior sensação de segurança, por causa da confiança nas relações prévias entre as franqueadas.

\subsection{Benefícios e dificuldades}

As principais vantagens apresentadas pelos entrevistados referem-se a dois aspectos: (a) economia nos preços de aquisição; (b) benchmarking entre franqueadas e com a empresa terceirizada. A rede também permitiu aprendizado, uniformização de materiais utilizados e melhoria nos processos internos das áreas de compras.

Os documentos Doc5 e Doc6 apresentam estimativas parciais de ganhos por contratos já firmados e outros ainda em negociação à época, o que elevou a expectativa para economias de $7 \%$ nas compras das categorias. O Doc8 apresenta os ganhos obtidos em contratos de diferentes prazos, todos já firmados, nas categorias listadas no Quadro 3, que cumpriram as 6 etapas da operacionalização da rede. Os resultados financeiros indicam economia efetiva de 2 milhões de reais, 5,3\% do volume financeiro negociado, comprovando a expectativa de economias de escala (PINDYCK; RUBINFELD, 2010).

Os ganhos pela economia dos custos de transação ocorreram na centralização das negociações, reduzindo o número de fornecedores e a frequência dos processos de compra, e pela elaboração de contratos de médio prazo (em sua maioria de 1 a 3 anos). No entanto, segundo os entrevistados, havia uma expectativa de redução na estrutura das franqueadas, o que não ocorreu. Isso foi necessário, pois somente as atividades de desenvolvimento de fornecedores e negociação de preços foram transferidas para a rede, não reduzindo parte dos custos. Assim, os custos de transação não foram foco principal, mas os ganhos de preço obtidos pela escala.

Como esperado na escolha dos parceiros da rede na fase do projeto, as economias obtidas em organizações de portes semelhantes também se comportaram da mesma forma. As franqueadas A, C e D obtiveram economias de $4 \%, 6 \%$ e $4 \%$, enquanto a menor delas, franqueada B, obteve $12 \%$, confirmando o pressuposto de que empresas menores possuem custos de compra superiores, tendo maiores benefícios com a rede.

Os ganhos não financeiros foram apontados pelos entrevistados e identificados nos documentos analisados, assim como durante a observação. No Doc6 é destacado o "potencial aumento dos 
benefícios gerados através da padronização de processos, especificações, nível de serviço e condições comerciais". Nas observações, os participantes do setor de compras da franqueada B mostraram os documentos de padronização dos materiais por meio dos quais aprenderam sobre novas características de itens que já utilizavam. Questões sobre rotinas dos processos de compras e a indicações de fornecedores são trocas que passaram a existir mais fortemente entre as franqueadas, para as categorias ainda negociadas fora da rede. O compartilhamento de experiências entre os funcionários das franqueadas também foi um ponto destacado pelo EntrB, como potencial para sinergias em novas atividades conjuntas.

Outros aspectos foram identificados nas apresentações utilizadas em reuniões ou destacados pelos participantes como limitações ou desvantagens da atuação na rede de compras. O EntrB destacou a perda de autonomia e flexibilidade de ação, impedindo negociações individuais que gerem economias, mesmo quando apresentadas por em propostas de possíveis novos fornecedores. O EntrB ilustrou o caso de contato voluntário de um fornecedor que apresentava preços menores para negociação, porém sem potencial de atender todos os integrantes da rede. Essa abordagem de fornecedores às franqueadas foi mencionada também pelo EntrA como potencial ameaça de enfraquecimento da rede, caso alguma franqueada perceba tais economias como melhor prática.

Outros pontos destacados como limitadores desse processo em rede estão relacionados a sua implantação. Os contratos já existentes nas franqueadas com seus fornecedores e as multas de rescisão podem incorrer em maior tempo de entrada de um parceiro na rede ou da obtenção dos benefícios de determinada categoria. Mesmo sendo um processo normal em transições, isso incorre em menores volumes de compra, o que potencialmente reduz o poder de barganha e as economias de escala.
Além disso, dificuldades de uniformidade das especificações técnicas entre os parceiros da rede e resistência das áreas consumidoras nas empresas foram destacados pelos entrevistados. Isso impediu, por exemplo, que as negociações de plano de saúde para funcionário fossem feitas pela rede. Mesmo que o processo de atuação conjunta precise de harmonização, sua não ocorrência resulta no mesmo efeito do limitador anterior, volume de compra inferior e potencial redução nas economias de escala.

\subsection{Discussão dos fatores condicionantes e resultados}

A escolha dos parceiros é um dos fatores considerados críticos na criação de redes (MEDCOF, 1997; WEBER e SPARKS, 2004) que apresenta elementos que contribuem para a formação da aliança analisada. São fatores promotores dessa escolha o sistema de franquia, com relações já existentes, a maturidade da franquia, a continuidade dos franqueados (BAUCUS; BAUCUS, HUMAN, 1996) e territórios de atuação definidos (MICHAEL, 2000), que não permitem competições de mercado entre os franqueados, assim como a própria relação contratual com a franqueadora em que há maior nível de comprometimento com o sistema.

Ainda, o fato de haver um pequeno número de empresas, todas de grande porte, está relacionado ao alto nível de investimentos em ativos específicos da rede, indicando maior autonomia nas decisões em relação à franqueadora. A especificidade dos ativos, elemento dos custos de transação (WILLIAMSON, 1989) foi identificado por Mumdziev e Windsperger (2013) como positivamente relacionado à alocação da decisão no franqueado, em que a confiança, tal como destacada pelos entrevistados desta pesquisa, se apresenta como fator moderador que contribui para essa realidade. 
Medcof (1997) e Wright e Grace (2011) abordam as questões de compatibilidade operacional, confiança e comprometimento, congruência de objetivos e cultura organizacional, fatores também identificados nessa pesquisa. Todas as franqueadas atuam de forma semelhante em suas atividades de produção, marketing e vendas, tendo produtos e processos padronizados pela estrutura de franquia. No entanto, apesar dessa semelhança nas operações principais, as demais atividades, nas quais são utilizados os produtos adquiridos pela rede, algumas especificações técnicas de cada franqueada impediram a efetivação de todas as categorias, tendo como principal exemplo a dificuldade de obtenção de serviços de qualidade em uma única operadora de telefonia móvel. Porém, os determinantes de não uniformidade estão mais relacionados à infraestrutura dos fornecedores do que às escolhas das empresas, mesmo que existam restrições internas.

Nessa linha, percebeu-se um nível mais elevado de comprometimento com a rede nas áreas diretamente envolvidas (setor de compras) e maior restrição a mudanças pelas áreas cliente dos produtos, demonstrando variações nos determinante comprometimento de Medcof (1997). Isso foi identificado nas entrevistas, sobre as áreas de Recursos Humanos (categoria refeição) e Tecnologia da Informação (categoria telefonia), o que pode enfraquecer as economias geradas e a própria rede. $\mathrm{O}$ EntrA reforçou a necessidade de tratamento dessas restrições nas próprias franqueadas, ou seja, abordar o problema individualmente e não pela rede.

O modelo de atuação em franquia permite uma maior percepção de confiança, fator igualmente previsto na literatura, tanto entre as empresas (BIERLY; GALLAGHER, 2007; SILVA; BRADLEY; SOUSA, 2012) pelas relações já existentes no ambiente da franquia (HOLMBERG; MORGAN, 2003; WRIGHT; GRACE, 2011; GILLIS; COMBS; KETCHEN JUNIOR, 2014) como pelas empresas atuarem em conjunto há muito tempo em outras atividades, como na compra de matérias-primas e realização de eventos. Da mesma forma, contribuíram para a formação da rede, a confiança e a proximidade entre os membros das organizações (BIERLY; GALLAGHER, 2007), demonstrando a importância das relações pessoais, identificadas entre os presidentes das franqueadas.

Os benefícios financeiros percebidos durante a pesquisa são fatores importantes que condicionam a existência da rede, pois são seu objetivo e promovem a continuidade do interesse dos participantes, alinhados a Medcof (1997) e Chatterjee (2002). Os ganhos obtidos no projeto foram demonstrados em apresentações feitas pela empresa terceirizada aos integrantes da rede (Doc5, Doc6 e Doc8). A continuidade do interesse das franqueadas que iniciaram e a inserção das demais na aliança, que perceberam a economia de custos, também são indicativas desse fator, tal como encontrado no estudo de Chatterjee (2002). No entanto, esse fator é moderado pelo ambiente de franquia, que promove a participação de todos, assim como pelo porte, em que a maior empresa decidiu por não operar em conjunto.

A premissa de motivação da formação de uma aliança interorganizacional, da obtenção de recursos que sozinha uma empresa não conseguiria, ficou evidente tanto nas entrevistas, pelo interesse na consolidação dos volumes de compra e obtenção de ganhos de escala, como no Doc3. Nesse documento há a demonstração da expectativa de ganho de uma das franqueadas, caso contratasse a empresa terceirizada para fazer suas compras. Indica economia de 3\% caso atuasse sozinha e 6\% se operasse suas compras pela rede.

Alinhado à RBV (BARNEY, 1991; 1995), o acesso a conhecimentos e experiências (EBERS, 2001; SOEKIJAD e ANDRIESSEN, 2003) estão presentes nas entrevistas como uma consequência das trocas de documentos e conversas entre as áreas de compras das franqueadas, bem como o compromisso da empresa terceirizada em repassar isso a elas. 
Foi destacado também o acesso a fornecedores e conhecimentos sobre especificações de produtos, tal como aquisição de energia elétrica em mercado livre e a utilização de paletes antes considerados inadequados. No entanto, isso ficou mais destacado entre as franqueadas que tinham menor contato anterior. O EntrC salientou que já havia uma sinergia mais forte com a franqueada $D$, o que resultou em menores ganhos nesse sentido, pois já atuavam conjuntamente em outras atividades, inclusive pela proximidade física entre elas.

No ambiente da franquia as questões de proteção à entrada de novos concorrentes (POULIS; YAMIN; POULIS, 2012) e inserção em novos mercados (CHETTY; WILSON, 2003) não são fatores condicionantes da existência da rede. O primeiro está relacionado ao fato de a empresa não se associar a um concorrente com o qual divide determinado mercado e o segundo pela impossibilidade da franqueada atuar fora dos limites territoriais definidos em contrato com a franqueadora. No entanto, esses mesmos fatores que inibem o crescimento da nova rede restringem o crescimento individual das franqueadas e contribuem para a alternativa encontrada por elas para melhorar o desempenho.

Assim, a coopetição (BENGTSSON; KOCK, 2000) não é um fator determinante da relação analisada, levando à existência de pontos dos acordos regulados apenas pela confiança entre as franqueadas, como questões de atrito com fornecedores e saídas da rede. Elas formam a rede para cooperar, o que reduz custos (DAHLSTROM; NYGAARD, 1999), porém não competem diretamente. A competição não ocorre no nível de mercado, mas há a possibilidade de uma franqueada adquirir outra e a semelhança das operações é um fator contributivo para isso. O EntrA apresentou a competição para fora da rede, quando falou da economia de custos, destacando as franqueadas menores e a necessidade de serem mais competitivas. Isso, mesmo que indiretamente, contribui para redução da incerteza da incorporação entre companhias.
Por fim, foi identificado que a relação de franquia, mesmo que contribua para redução de risco e maior confiança, assim como aproxima parceiros para a formação de rede, afasta novos integrantes. Não há previsão para entrada de novos parceiros de fora do sistema de franquia já existente, o que limita a expansão da consolidação dos volumes, fator que motivou a criação da rede de compras. Outro limitador dessa realidade ocorre pelo controle da franqueadora sobre os materiais primários, restando para as franqueadas uma maior liberdade exclusivamente na compra dos demais itens relativos à escolha dos materiais e dos fornecedores. Esses materiais secundários correspondem, no caso estudado, a 1/3 do valor total de aquisições das franqueadas. Esse é um fator relevante, e sua análise prévia é importante para conhecer as potenciais economias de escala e oscilações nos custos de transação por estruturas adicionais de manutenção da rede.

\section{CONCLUSÃO}

A presente pesquisa abordou a formação de uma rede horizontal entre franqueadas para a consolidação de volumes de compras, independentemente da relação formada pela franquia em que atuam. Fatores apontados por Powell (1990) como a complementariedade, o ambiente relacional, o médio grau de flexibilidade, o alto grau de compromisso e a visão de benefícios mútuos foram identificados, com redução da importância da preocupação com a reputação da rede e a resolução de conflitos, por causa do maior grau de confiança já existente, tendo por base as relações existentes no ambiente da franquia.

Foi identificada, como principal motivadora, a economia de custos de compras, pelos ganhos de escala (PINDYCK; RUBINFELD, 2010). No entanto, as economias de custos de transação ocorreram parcialmente, uma vez que as estruturas das empresas foram mantidas, sendo uma oportunidade 
ainda não explorada. A troca de conhecimentos e experiências aparece como um ganho não financeiro para as franqueadas, alinhada à RBV (GILLIS; COMBS; KETCHEN JUNIOR, 2014).

O ambiente de franquia contribuiu para aproximação dos participantes da rede, pelo conhecimento prévio e atuação conjunta, reduzindo incertezas de comportamento (MUMDZIEV; WINDSPERGER, 2013; JELL-OJOBOR; WINDSPERGER, 2014) e promovendo maior confiança. No entanto, eleva os riscos vinculados no nível de confiança, como a não previsão do tratamento de litígios, assim como eventuais desistências de integrantes por causa da incompletude dos contratos (SOLIS-RODRIGUEZ; GONZALEZ-DIAZ, 2012), o que elevaria os custos de transação ex ante para evitar os ex post (WILLIAMSON, 1989; MICHAEL, 2000).

A atuação em franquia também limita a expansão da rede, pois o ambiente é fechado nas relações já existentes, impedindo crescimentos adicionais na consolidação dos volumes de outras empresas de fora da franquia e nas compras de materiais primários, regulados pela franqueadora. Entretanto, percebe-se que os mesmos fatores que inibem o crescimento da nova rede restringem o crescimento individual das franqueadas e contribuem para a alternativa encontrada por elas para melhorar o desempenho, ou seja, a partir restrição é gerada a oportunidade.

No entanto, os limites definidos pela franqueadora são elementos importantes da relação, evitando comportamentos prejudiciais à marca $\mathrm{e}$ ao nome da franquia (COMBS; KETCHEN JUNIOR, 2003; COCHET; DORMAN; EHRMANN, 2008). No caso analisado, ela está próxima à rede formada pelas franqueadas com interesse em obter os mesmos benefícios de economia de custos, o que aumenta o nível de governança por controles relacionais sobre o comportamento dos franqueados, elevando os custos de agência (GILLIS; COMBS; KETCHEN JUNIOR, 2003; COCHET; DORMAN; EHRMANN, 2008).
Essa pesquisa contribui tanto para a literatura de redes de empresas como, em particular, para as franquias ao discutir elementos de autonomia de empresas franqueadas e a formação de redes entre elas, indicando fatores determinantes e os principais limitadores. Analisar tal situação pelo lado positivo requer o foco na nova rede, tal como aqui realizado, o que abre caminho para estudos relacionados aos modelos de governança e o papel da franqueadora, tendo configuração passiva nessa relação. Para as empresas, demonstra-se uma nova forma de obter ganhos mesmo em um ambiente com baixa liberdade de ação e com maior nível de regulação contratual.

Mesmo com as contribuições identificadas, seus resultados estão vinculados ao caso analisado em que as relações de franquia são de longo prazo, porém a rede está em consolidação. Também há um número limitado de franqueadas atuando, sendo todas de grande porte. Provavelmente em ambientes com maior número de franqueadas de médio e pequeno porte essas relações sejam diferentes, principalmente pelos custos adicionais de negociação e a multiplicidade de opiniões. Os custos de transação para criação e consenso entre membros da rede de franqueadas podem, inclusive, não compensar as economias de escala da atuação em conjunto, devido ao número de empresas participantes.

A existência de uma associação de franqueados, com papel de comando e hierarquia de decisões, pode reduzir tais custos, configurando-se como uma organização adicional ao próprio sistema de franquia. Nesse sentido, novas pesquisas também podem contribuir para os estudos sobre redes em ambientes com limites contratuais de ação, como as franquias, assim como realizadas em relações mais pulverizadas e empresas de menor porte. A busca por redes com maior tempo de atuação também poderá suprir lacunas identificadas nesse estudo, como a existência de contratos incompletos. 


\section{REFERÊNCIAS}

ABF. Associação Brasileira de Franqueadores. Desempenho 2013-2012. 2014. Disponível em: $<$ http://www.portaldofranchising.com.br/numerosdo-franchising/desempenho-2013-2012>. Acesso em: 31 ago. 2014.

BADIR, Y. F.; BÜCHEL, B.; TUCCI, C. L. A conceptual framework of the impact of NPD project team and leader empowerment on communication and performance: an alliance case context. International Journal of Project Management, v. 30, n. 8, p. 914926, nov. 2012.

BARDIN, L. Análise de conteúdo. 4. ed. Lisboa: Edições 70, 2010.

BARNEY, J. Firm resources and sustained competitive advantage. Journal of Management, v. 17, n. 1, p. 99-120, 1991.

Looking inside for competitive advantage. The Academy of Management Executive, v. 9, n. 4, p. 49-61, 1995.

BAUCUS, D. A.; BAUCUS, M. S.; HUMAN, S. E. Consensus in franchise organizations: a cooperative arrangement among entrepreneurs. Journal of Business Venturing, v. 11, p. 359-378, 1996.

BENGTSSON, M.; KOCK, S. "Coopetition" in business networks: to cooperate and compete simultaneously. Industrial Marketing Management, v. 29, p. 411-426, set. 2000.

BIERLY, P. E.; GALLAGHER, S. Explaining alliance partner selection: fit, trust and strategic expediency. Long Range Planning, v. 40, n. 2, p. 134-153, abr. 2007.

CAGLIO, A.; DITILLO, A. A review and discussion of management control in inter-firm relationships: achievements and future directions. Accounting, Organizations and Society, v. 33, n. 7-8, p. 865-898, out. 2008.

CASTROGIOVANNI, G. J.; COMBS, J. G.; JUSTIS, Robert T. Shifting imperatives: an integrative view of resource scarcity and agency reasons for franchising. Entrepreneurship Theory and Practice, v. 30, n. 1, p. 2340, 2006.

CHATTERJEE, P. Interfirm alliances in online retailing. Journal of Business Research, v. 57, p. 714-723, jul. 2002.

CHETTY, S. K.; WILSON, H. I. M. Collaborating with competitors to acquire resources. International Business Review, v. 12, n. 1, p. 61-81, fev. 2003.

COCHET, O.; DORMANN, J.; EHRMANN, T. Capitalizing on franchisee autonomy: relational forms of governance as controls in idiosyncratic franchise dyads. Journal of Small Business Management, v. 46, n. 1, p. 50-72, 2008.

COMBS, J. G.; KETCHEN JUNIOR, D. J. Why do firms use franchising as an entrepreneurial strategy?: a metaanalysis. Journal of Management, v. 29, n. 3, p. 443465, 2003.

COMBS, J. G.; KETCHEN JUNIOR, D. J.; HOOVER, V. L. A strategic groups approach to the franchisingperformance relationship. Journal of Business Venturing, v. 19, p. 877-897, 2004.

COMBS, J. G.; MICHAEL, S. C.; CASTROGIOVANNI, G. J. Franchising: a review and avenues to greater theoretical diversity. Journal of Management, v. 30, n. 6, p. 907931, 2004.

COMMONS, J. R. Institutional Economics. American Economic Review, v. 21, p. 648-657, 1931. 


\section{REFERÊNCIAS}

CUMMINGS, J. L.; HOLMBERG, S. R. Best-fit alliance partners: the use of critical success factors in a comprehensive partner selection process. Long Range Planning, v. 45, n. 2, p. 134-153, abr. 2012.

DAHLSTROM, R.; NYGAARD, A. An empirical investigation of ex post transaction costs in franchised distribution channels. Journal of Marketing Research, v. 36, p. 160-170, 1999.

DANT, R. P.; KAUFMANN, P. J. Structural and strategic dynamics in franchising. Journal of Retailing, v. 79, p. 63-75, 2003.

DANT, R. P.; KAUFMANN, P. J.; PASWAN, A. K. Ownership redirection in franchised channels. Journal of Public Policy \& Marketing, v. 11, n. 1, p. 33-44, 1992.

DEVLIN, G.; BLEACKLEY, M. Strategic Guidelines for success. Long Range Planning, v. 21, n. 5, p. 1823, 1988.

DONG, L.; GLAISTER, K. W. Motives and partner selection criteria in international strategic alliances: perspectives of chinese firms. International Business Review, v. 15, n. 6, p. 577-600, dez. 2006.

EBERS, M. Interorganizational relationships and networks. In: International Encyclopedia of the Social \& Behavioral Sciences, p. 7855-7860.

FRAZER, L. Causes of disruption to franchise operations. Journal of Business Research, v. 54, n. 3, p. 227-234, dez. 2001.

GILLESPIE, J.; GULATI, R. Alliances and joint ventures: organizational. In: International Encyclopedia of the Social \& Behavioral Sciences, p. 392-397.
GILLIS, W. E.; COMBS, J. G.; KETCHEN JUNIOR, D. J. Using resource-based theory to help explain plural form franchising. Entrepreneurship Theory and Practice, v. 38, n. 3, p. 449-472, 2014.

GODOY, A. S. Introdução à pesquisa qualitativas e suas possibilidades. Revista de Administração de Empresas, v. 23, n. 2, p. 57-63, 1995.

GULATI, R. Alliances and networks. Strategic Management Journal, v. 19, n. 4, p. 293-317, abr. 1998.

HOFFMANN, W. H.; SCHLOSSER, R. Success factors of strategic alliances in small and medium-sized enterprises: an empirical survey. Long Range Planning, v. 34, p. 357381, jun. 2001.

HOLMBERG, S. R.; MORGAN, K. B. Franchise turnover and failure. Journal of Business Venturing, v. 18, n. 3, p. 403-418, maio 2003.

JELL-OJOBOR, M.; WINDSPERGER, J. The choice of governance modes of international franchise firms: development of an integrative model. Journal of International Management, v. 20, p. 153-187, 2014.

KLEIN, B. The economics of franchise contracts. Journal of Corporate Finance, v. 2, p. 9-37, 1995.

MEDCOF, J. W. Why too many alliances end in divorce. Long Range Planning, v. 30, n. 5, p. 718-732, out. 1997.

MICHAEL, S. C. Investments to create bargaining power: the case of franchising. Strategic Management Journal, v. 21, p. 497-514, 2000.

MUKHERJEE, A. Franchise management: a model of service-quality interactions. International Journal of Quality \& Reliability Management, v. 20, n. 3, p. 325344, 2003. 


\section{REFERÊNCIAS}

MUMDZIEV, N.; WINDSPERGER, J.. An extended transaction cost model of decision rights allocation in franchising: the moderating role of trust. Managerial and Decision Economics, v. 34, p. 170-182, 2013.

NAULT, B. R. Mitigating underinvestment through an IT-enabled organization form. Organization Science, v. 8, n. 3, p. 223-234, 1997.

NAULT, B. R.; DEXTER, A. S. Adoption, transfers and incentives in a franchise network with positive externalities. Marketing Science, v. 13, n. 4, p. 412423, 1993.

PASWAN, A. K.; WITTMANN, C. M. Knowledge management and franchise systems. Industrial Marketing Management, v. 38, n. 2, p. 173-180, fev. 2009.

PAULINO, M. L. S. Sistemas de controle administrativo no franchising: aliando controle e flexibilidade estratégica. Revista Organizações em Contexto, v. 6, n. 12, p. 28-55, 2010.

PINDYCK, R. S.; RUBINFELD, D. L. Microeconomia. 7. ed. São Paulo: Pearson Education do Brasil, 2010. p. 647

POULIS, K.; YAMIN, M.; POULIS, E. Domestic firms competing with multinational enterprises: the relevance of resource-accessing alliance formations. International Business Review, v. 21, n. 4, p. 588601, ago. 2012.

POWELL, W. W. Neither market nor hierarchy: network forms of organization. Research in Organizational Behavior, v. 12, p. 295-336, 1990.

RANGAN, U. S.; YOSHINO, M. Y. Forging alliances: a guide to top. The Columbia Journal of World Business, v. 31, n. 3, p. 6-13, 1996.
RUBIN, P. An empirical look at franchising as an organizational form. Journal of Business, v. 61, n. 2, p. 197-217, 1978.

SILVA, S. C. E; BRADLEY, F.; SOUSA, C. M. P. Empirical test of the trust-performance link in an international alliances context. International Business Review, v. 21, n. 2, p. 714-723, abr. 2012.

SOEKIJAD, M.; ANDRIESSEN, E. Conditions for knowledge sharing in competitive alliances. European Management Journal, v. 21, n. 5, p. 578-587, out. 2003.

SOLIS-RODRIGUEZ, V.; GONZALEZ-DIAZ, M. How to design franchise contracts: the role of contractual hazards and experience. Journal of Small Business Management, v. 50, n. 2, p. 652-677, 2012.

STEPHENSON, P. R.; HOUSE, R. G. The design of an effective relationship. Business Horizons, v. 14, n. 4, p. 35-42, 1971.

TRIVIÑOS, A. N. S. Introdução à pesquisa em ciências sociais: a pesquisa qualitativa em educação. São Paulo: Atlas, 1987.

WEBER, K.; SPARKS, B. Consumer attributions and behavioral responses to service failures in strategic airline alliance settings. Journal of Air Transport Management, v. 10, n. 5, p. 361-367, set. 2004.

WILLIAMSON, O. E. Transaction-cost economics: the governance of contractual relations. Journal of Law and Economics, v. 22, n. 2, p. 233-261, 1979.

Las instituciones económicas del capitalismo. Cidade do México: Fondo de Cultura Económica, 1989.

WRIGHT, O.; GRACE, A. Trust and commitment within franchise systems: an Australian and New Zealand perspective. Asia Pacific Journal of Marketing and Logistics, v. 23, n. 4, p. 486-500, 2011. 


\section{REFEREANCIAS}

YIN, R. K. Estudo de caso: planejamento e métodos. 3. ed. Porto Alegre: Bookman, 2005.
YOSHINO, M. Y.; RANGAN, U. S. Alianças estratégicas. São Paulo: Makron Books, 1996. p. 263. 